\section{Triple cycle audit of primary retinal detachment surgery}

\author{
Z Johnson ${ }^{1}$, A Ramsay ${ }^{1}$, D Cottrell ${ }^{1}$, K Mitchell $^{2}$, \\ K Stannard ${ }^{1}$

\section{K Stannard 10}

Abstract

Eye (2002) 16, 513-518. doi:10.1038/

sj.eye. 6700143

Purpose To determine the effect of increasing subspecialisation on the results of retinal detachment surgery in one city. Methods Three audit cycles over a 10-year period when major subspecialisation and organisational changes were occurring. Retrospective case note reviews of all primary surgery for rhegmatogenous retinal detachments in each of the audit periods. Statistical analyses used contingency table/chi-square methods for comparing all three audits and Fisher's exact test/mean odds ratio with $95 \%$ confidence intervals (CIs) for the Audit 1 vs Audit 3 comparison. Results A marked improvement in success rates occurred: primary reattachment rose from $67 \%$ in Audit 1 to $87 \%$ in Audit 3 $(P=0.0004)$, and final success from $84 \%$ to 97\% $(P=0.0003)$. There was a dramatic change in operative techniques over the same period: the percentage of vitrectomies increased from $1.5 \%$ in Audit 1 to $48 \%$ in Audit 3, while that of 'open' conventional procedures decreased from $78 \%$ to $32 \%$. However, the improvement in anatomical success was not mirrored by an increase in the percentage of patients with $6 / 12$ or better visual acuity postoperatively (55\% in Audit 1, $49 \%$ in Audit 3; $P=0.34$, mean odds ratio $=0.78 ; 95 \% \mathrm{CI} 0.48-1.2)$. The percentage of patients with $6 / 18-6 / 36$ post op visual acuity did increase in Audit 3 (18\% in Audit 1; $29 \%$ in Audit 3; $P=0.03$, mean odds ratio $=1.9 ; \mathrm{CI} 1.1-3.3$ ), and the percentage with $6 / 60$ or worse decreased $(27 \%$ in Audit $1,20 \%$ in Audit 3; $P=0.26$, mean odds ratio $=0.71$; CI $0.40-1.2$ ).

Conclusions With increased subspecialisation there has been an increase in anatomical success, but the goal of $\mathbf{1 0 0 \%}$ reattachment is still not being attained. There remains scope for further improvement in anatomical and functional outcomes.
Keywords: retinal detachment; scleral buckling; vitrectomy; treatment outcome; audit

Introduction

The last 10 years have seen a major increase in subspecialisation within ophthalmology, especially in the field of retinal surgery. At the same time the value of clinical audit has been increasingly recognised. Since

subspecialisation introduces significant problems into the planning and organisation of clinical services, especially for urgent or semi-urgent conditions, it is appropriate to use audit to assess whether it brings genuine benefits.

The literature contains surprisingly few audits of the success rate of retinal detachment surgery. One of the first was in 1973 and reported a primary success rate of $75 \%$ and a final success rate of $88 \% .^{1}$ This rate had not changed significantly by 1988 when Tornquist and Tornquist reported a $77.1 \%$ primary anatomical success rate. ${ }^{2}$ These served to set baseline standards by which results of detachment surgery could be compared. More recently, Sullivan et $a l^{3}$ reported an audit comparing current results with those of 23 years previously, showing primary and final success rates increasing from $75 \%$ and $88 \%$ to $80 \%$ and $97 \%$ respectively, but this was not found to be statistically significant. However that study is interpreted as showing the effects of advancing surgical techniques rather than increased subspecialisation.

A recent paper from Comer et al showed an increase in primary success rates from $76.1 \%$ in $1989-90$ to $88.8 \%$ in $1995-97$, during a period of increasing subspecialisation. ${ }^{4}$ The Royal College of Ophthalmologists UK retinal detachment audit showed a trend to improved outcome in subspecialist hands, with VR

\author{
'Department of \\ Ophthalmology \\ Royal Victoria Infirmary \\ Newcastle upon Tyne, UK \\ 2Regional Department of \\ Medical Physics \\ Royal Victoria Infirmary \\ Newcastle upon Tyne, UK \\ Correspondence: \\ DG Cottrell, FRCOphth \\ Department of \\ Ophthalmology \\ Claremont Wing \\ Royal Victoria Infirmary \\ Queen Victoria Road \\ Newcastle upon Tyne \\ NE1 4LP, UK \\ Tel: 01912325131 \\ Fax: 01912275246 \\ E-mail: D.G.Cottrell@ \\ ncl.ac.uk \\ Presented at: \\ 'Audit at the Cutting \\ Edge', Royal College of \\ Ophthalmologists Audit \\ Day, May 1998 \\ British and Eire Association \\ of Vitreoretinal Surgeons \\ Meeting October 1998, \\ Leeds
}


Table 1 Details of the three retinal detachment audits performed

\begin{tabular}{lcccc}
\hline Audit & Dates & $\begin{array}{c}\text { Total number } \\
\text { of cases }\end{array}$ & $\begin{array}{c}\text { Number of } \\
\text { notes found }\end{array}$ & $\begin{array}{c}\% \text { of notes } \\
\text { found }\end{array}$ \\
\hline 1 & $1987-89$ & 141 & 135 & 96 \\
2 & $1990-93$ & 205 & 195 & 96 \\
3 & $1996-97$ & 142 & 142 & 100 \\
\hline
\end{tabular}

specialists having an overall re-attachment rate of $92.8 \%$ compared to $88.4 \%$ from non-specialists. ${ }^{5}$

If subspecialisation is to be recommended firmly, it is important to see whether these encouraging results can be repeated in other centres. We therefore present the results of three retinal detachment audits performed in Newcastle upon Tyne between 1987 and 1997. The results of the first two audits led to a progressive shift in policy on who performed retinal detachment surgery, culminating in the establishment in 1996 of a two-consultant vitreoretinal team (in an amalgamated unit) taking all retinal detachments.

\section{Materials and methods}

Cases were identified from the theatre record book, and a retrospective case note review of all primary surgery for rhegmatogenous retinal detachment was performed for three study periods between 1987 and 1997 (Table 1).

Twenty-five categories of information per patient were collected using the same data record sheet for each audit. Results were analysed using Microsoft Access database. Follow up averaged over 9 months in each cycle, the details being shown in Table 2 .

In each cycle the audit standard was set at 100\% anatomical reattachment. The definition of primary success was retinal reattachment after a single operation persisting for at least 3 months.

Statistical analyses used contingency table and chisquare methods to assess significance when comparing all three audits and Fisher's exact test for assessing significance in the Audit 1 vs Audit 3 comparison. Mean odds ratio with associated $95 \%$ confidence intervals (CI) were also calculated to give an indication of the magnitude of the differences and their spread.

Table 2 Follow-up periods

\begin{tabular}{lccc}
\hline Audit & Mean follow-up & $\begin{array}{c}\text { \% with } 3 / 12 \\
\text { or more }\end{array}$ & $\begin{array}{c}\% \text { with } 6 / 12 \\
\text { or more }\end{array}$ \\
\hline 1 & 15.2 months & $93 \%$ & $86 \%$ \\
2 & 12.8 months & $90 \%$ & $85 \%$ \\
3 & 9.5 months & $96 \%$ & $91 \%$ \\
\hline
\end{tabular}

\section{Results}

\section{Audit 1}

During the first audit (1987-89), retinal detachments were repaired by the ophthalmic team on-call for that day. Only one of these consultant led teams (DGC) had a specific vitreo-retinal (V-R) interest. The V-R team usually accepted referrals from colleagues only if primary repair by them had failed. Sixty-three per cent of the operations were by consultants with $18 \%$ by juniors under direct supervision. The combined primary success rate was $67 \%$ with a final success rate of $84 \%$ (Table 3). However this concealed an unacceptable variability in teams' performances, which ranged from $45 \%$ to $79 \%$ primary success and $73 \%$ to $93 \%$ final success.

As a result of Audit 1, two recommendations were made. The first was to make a primary referral of difficult retinal detachment cases directly to the consultant with a V-R interest, or at least to seek his advice prior to surgery. 'Difficult detachments' were those that the original surgeon felt unable to deal with. The second recommendation was for one firm to cease doing detachments entirely. The recommendations were unanimously accepted and implemented.

\section{Audit 2}

By the second audit (1990-93) the combined primary success rate had improved from $67 \%$ to $73 \%$ and the final reattachment rate rose from $84 \%$ to $92 \%$ (Table 3). General ophthalmologists achieved $70 \%$ primary success, and $93 \%$ final success with the help of secondary V-R intervention. In this audit period

Table 3 Anatomical outcome of retinal detachment surgery

\begin{tabular}{|c|c|c|c|}
\hline Audit 1 & Total $(n=135)$ & $\begin{array}{l}\text { With } 3 / 12 \\
\text { follow-up } \\
(n=125)\end{array}$ & $\begin{array}{l}\text { With } 6 / 12 \\
\text { follow-up } \\
(n=116)\end{array}$ \\
\hline Primary success & $67 \%$ & $65 \%$ & $64 \%$ \\
\hline Final success & $84 \%$ & $83 \%$ & $83 \%$ \\
\hline Audit 2 & Total $(n=198)$ & $\begin{array}{l}\text { With } 3 / 12 \\
\text { follow-up } \\
(n=176)\end{array}$ & $\begin{array}{l}\text { With 6/12 } \\
\text { follow-up } \\
(n=168)\end{array}$ \\
\hline Primary success & $73 \%$ & $72 \%$ & $71 \%$ \\
\hline Final success & $92 \%$ & $91 \%$ & $90 \%$ \\
\hline Audit 3 & Total $(n=142)$ & $\begin{array}{l}\text { With } 3 / 12 \\
\text { follow-up } \\
(n=137)\end{array}$ & $\begin{array}{l}\text { With } 6 / 12 \\
\text { follow-up } \\
(n=129)\end{array}$ \\
\hline Primary success & $87 \%$ & $86 \%$ & $87 \%$ \\
\hline Final success & $97 \%$ & $97 \%$ & $97 \%$ \\
\hline
\end{tabular}


referrals of 'difficult' primary cases represented 53\% of the V-R team's workload, but despite this the V-R team achieved $76 \%$ primary success and $90 \%$ final success. Additionally, 24 of the general ophthalmologists' 31 primary failures had further surgery by the V-R team.

In order to determine if there was a group of simple detachments that the generalist could deal with, a subgroup of macular-on detachments with just one hole and one or two quadrants detached were studied. Out of 22 such cases operated on by generalists, seven had primary failures. Of the 11 such cases operated on by the V-R team, none had primary failure. Looking at all macular-on detachments, 11 out of 34 were primary failures for the generalist while only two out of 26 were for the V-R team (one having the original operation performed while the consultant was away) $(P=0.028$ odds ratio $0.17,95 \% \mathrm{CI}=0.04-0.87)$.

\section{Audit 3}

Following Audit 2, a major reorganisation of eye services took place where two departments merged allowing the formation of an enlarged V-R team (DGC and KPS) that was able to take all new detachments. General firms ceased doing retinal surgery entirely. Consultants performed $74 \%$ of the operations. Primary success rose to $87 \%$ and final success to $97 \%$ (Table 3).

The changes in rates of anatomical reattachment show an improvement that is highly statistically significant $(P=0.0004$, Chi-square test).

\section{Patient characteristics}

To determine if there was any significant difference between the groups of patients in each audit cycle we compared patient characteristics in Audits 1 and 3 (Figure 1). They proved to be remarkably similar. The

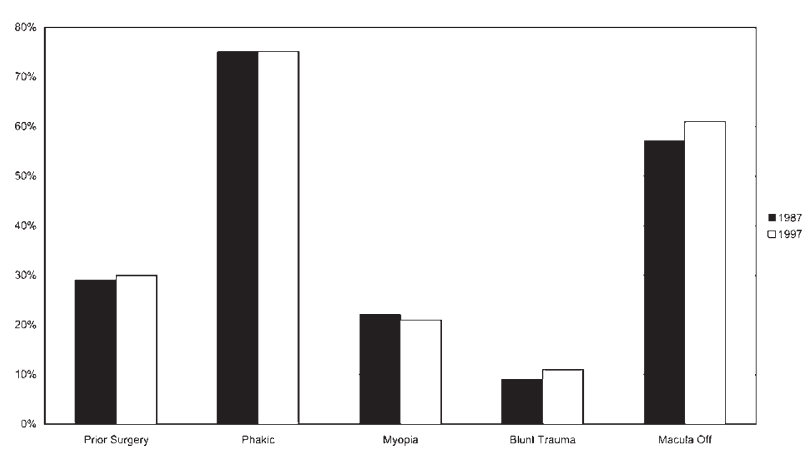

Figure 1 Patient characteristics. configurations of the detachments were also broadly similar (Figure 2a-c).

\section{Surgical techniques}

The surgical techniques changed substantially during the 10 years of this audit. Use of vitrectomy rose from $1.5 \%$ in Audit 1 to $47.9 \%$ of cases in Audit 3 .

Conversely, the proportion of 'open' conventional
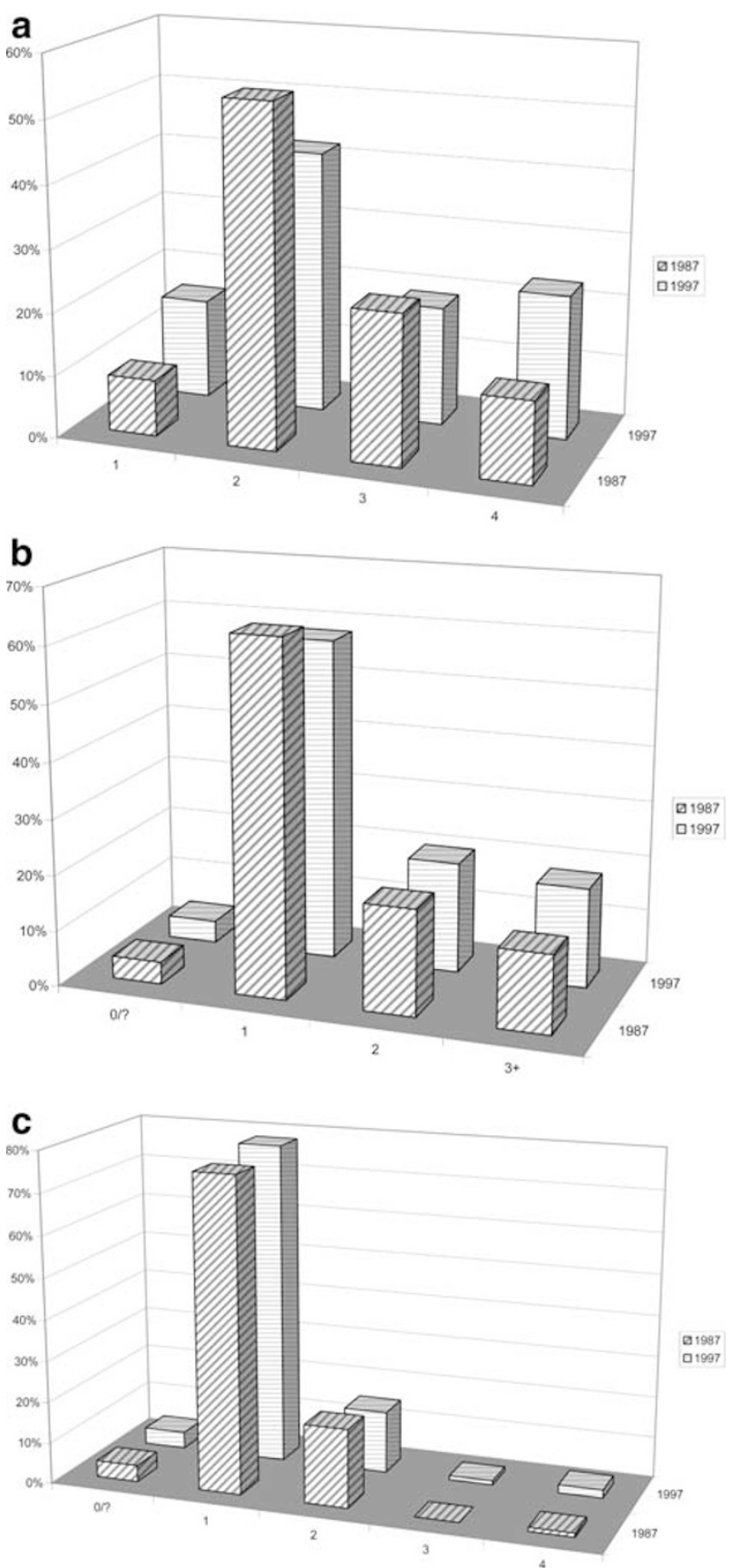

Figure 2 (a) Number of quadrants detached. (b) Number of breaks. (c) Number of quadrants with breaks. 
Table 4 Operation type

\begin{tabular}{lcc}
\hline Operation & Audit 1 & Audit 3 \\
\hline Vitrectomy & $2(1.5 \%)$ & $68(48 \%)$ \\
Pneumatic & 0 & $2(1.4 \%)$ \\
Conventional-closed & $28(20.7 \%)$ & $25(17.6 \%)$ \\
Conventional-open & $105(77.8 \%)$ & $46(32.4 \%)$ \\
\hline
\end{tabular}

Table 5 Types of 'open' conventional operations

\begin{tabular}{lcc}
\hline Operation & Audit 1 & Audit 3 \\
\hline Drain, no gas/air & $54(51.4 \%)$ & $12(26.1 \%)$ \\
Drain with gas/air & $50(47.6 \%)$ & $32(66.7 \%)$ \\
Gas/air, non drain & $1(1 \%)$ & $1(2 \%)$ \\
\hline
\end{tabular}

operations (those where drainage of sub-retinal fluid, and/or injection of gas or air was employed) fell from $77.8 \%$ to $32.4 \%$ of all detachments (Table 4 ).

Further comparison of the type of open conventional procedures showed an increase in the use of gas or air injection following drainage of sub-retinal fluid

(Table 5).

\section{Visual acuity}

In Audit 3 compared to Audit 1 there appeared to be a small decrease in the percentage of patients with the best postoperative visual acuity, and a greater percentage in the 6/18-6/36 group (Table 6). In

Figure 3, odds ratio data are shown for these figures; a significant increase in the percentage of patients with 6/18-6/36 postoperatively was evident $(P=0.03$, Fisher's exact test; $18 \%$ in Audit 1; $29 \%$ in Audit 3; odds ratio $=1.9 ; 95 \%$ CI 1.1-3.3). The results for the $6 / 12$ or better subgroup (55\% in Audit 1, 49\% in Audit 3 ; $P=0.34$; mean odds ratio $=0.78$; CI 0.48-1.2) and the $6 / 60$ or worse subgroup (27\% in Audit 1, 20\% in Audit $3 ; P=0.26$; mean odds ratio $=0.71 ; \mathrm{CI} 0.40-1.2)$, were not significant.

Table 6 Pre- and postoperative visual acuity

\begin{tabular}{lccccc}
\hline Visual acuity & \multicolumn{2}{c}{ Audit 1} & & Audit 3 \\
\cline { 2 - 3 } \cline { 5 - 6 } & $\begin{array}{c}\text { Preoper- } \\
\text { ative } \\
n=135\end{array}$ & $\begin{array}{c}\text { Postoperative } \\
n=135\end{array}$ & & $\begin{array}{c}\text { Preoperative } \\
n=142\end{array}$ & $\begin{array}{c}\text { Postoper- } \\
\text { ative } \\
n=142\end{array}$ \\
\hline $\begin{array}{l}\text { 6/12 or } \\
\text { better }\end{array}$ & $36(27 \%)$ & $75(55 \%)$ & & $42(30 \%)$ & $70(49 \%)$ \\
$6 / 18-6 / 36$ & $27(20 \%)$ & $24(18 \%)$ & & $31(22 \%)$ & $41(29 \%)$ \\
$6 / 60$ or & $61(45 \%)$ & $36(27 \%)$ & & $66(46 \%)$ & $29(20 \%)$ \\
worse & $11(8 \%)$ & 0 & & $3(2 \%)$ & $2(1 \%)$ \\
Unknown & & & & & \\
\hline
\end{tabular}

Chart 3

Odds Ratio: Audit 3 v. Audit 1

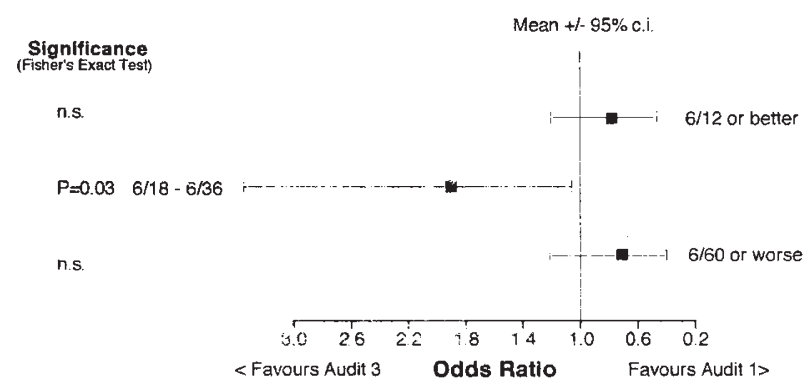

Figure 3 Odds ratio: Audit 3 vs Audit 1.

When the results are considered separately for those with macula-off and -on, there is a suggestion of improved results in Audit 3 for those with macula-off, but little change for those with macula-on (Table 7, data not available for all patients). However, none of the comparisons were statistically significant, although it must be conceded that the low numbers in certain subgroups confounded meaningful analysis.

\section{Reasons for primary failure}

Data on the reasons for primary failure are given for the V-R team and the generalists in Audit 2 and the totals for Audit 3 (Table 8). Numbers are too small for statistical analysis.

\section{Discussion}

\section{Improvement with increased subspecialisation}

These three retinal detachment audits show significant improvements in anatomical reattachment rates over a period in which there has been increasing subspecialisation in V-R surgery. Although referral routes varied somewhat between the audit cycles there

Table 7 Comparison of macula-on and macula-off cases

\begin{tabular}{|c|c|c|c|c|}
\hline \multirow[t]{2}{*}{ Visual acuity } & \multicolumn{2}{|c|}{ Macula-off } & \multicolumn{2}{|c|}{ Macula-on } \\
\hline & $\begin{array}{c}\text { Audit } 1 \\
n=63\end{array}$ & $\begin{array}{c}\text { Audit } 3 \\
n=86\end{array}$ & $\begin{array}{c}\text { Audit } 1 \\
n=49\end{array}$ & $\begin{array}{c}\text { Audit } 3 \\
n=56\end{array}$ \\
\hline $\begin{array}{l}\text { Improved } \\
\text { two or more } \\
\text { lines }\end{array}$ & $\begin{array}{c}33 \\
(52.4 \%)\end{array}$ & $\begin{array}{c}56 \\
(65.1 \%)\end{array}$ & $\begin{array}{c}10 \\
(20.4 \%)\end{array}$ & $\begin{array}{c}11 \\
(19.6 \%)\end{array}$ \\
\hline $\begin{array}{l}\text { Deteriorated } \\
\text { two or more } \\
\text { lines }\end{array}$ & $\begin{array}{c}3 \\
(4.8 \%)\end{array}$ & $\begin{array}{c}3 \\
(3.4 \%)\end{array}$ & $\begin{array}{c}6 \\
(12.2 \%)\end{array}$ & $\begin{array}{c}12 \\
(21.4 \%)\end{array}$ \\
\hline $\begin{array}{l}6 / 12 \text { or } \\
\text { better } \\
\text { postoperative }\end{array}$ & $\begin{array}{c}19 \\
(30.2 \%)\end{array}$ & $\begin{array}{c}33 \\
(38.4 \%)\end{array}$ & $\begin{array}{c}32 \\
(65.3 \%)\end{array}$ & $\begin{array}{c}37 \\
(66.1 \%)\end{array}$ \\
\hline
\end{tabular}


Table 8 Reasons for primary failure in Audit 2 and Audit 3

\begin{tabular}{|c|c|c|c|c|c|c|}
\hline \multirow[t]{2}{*}{ Reason } & \multicolumn{2}{|c|}{ Audit 2 generalists } & \multicolumn{2}{|c|}{ Audit 2 VR team } & \multicolumn{2}{|c|}{ Audit 3} \\
\hline & Number & $\%$ of primary failures & Number & $\%$ of primary failures & Number & $\begin{array}{c}\% \text { of primary } \\
\text { failures }\end{array}$ \\
\hline Iatrogenic break & 2 & $6 \%$ & 2 & $9 \%$ & 4 & $22 \%$ \\
\hline PVR & 4 & $13 \%$ & 3 & $14 \%$ & 2 & $11 \%$ \\
\hline Missed break & 4 & $13 \%$ & 1 & $5 \%$ & 2 & $11 \%$ \\
\hline Break not closed & 7 & $23 \%$ & 3 & $14 \%$ & 5 & $28 \%$ \\
\hline New break & 4 & $13 \%$ & 2 & $9 \%$ & 1 & $6 \%$ \\
\hline Uncertain & 10 & $32 \%$ & 11 & $50 \%$ & 4 & $22 \%$ \\
\hline
\end{tabular}

were only minimal differences in case mix (Figures 1 and 2). These improvements are likely to have occurred due to greater individual experience, an increasing range of treatment options (especially the increased availability of vitrectomy, see Table 4) and finally audit-driven, organisational change.

\section{Comparison with previous literature}

It can be difficult to make valid comparisons between audits from different centres, in view of variations in case mix and follow-up periods. Nevertheless, this study demonstrates comparable success rates to other centres. Audit 2's 74\% primary success compares with $76 \%$ reported in Bristol ${ }^{6}$ when a system of V-R surgeons prescribing, but often delegating, surgery was present in both units. Mersey Region quoted a primary success rate of $88 \%$ in 1995,7 compared with our $87 \%$ in Audit 3. The trend for an improvement with subspecialisation is very similar to that found in the recent Cambridge study. ${ }^{7}$

\section{Reasons for failure}

The audit standard of 100\% reattachment is not being attained. Information on reasons for failure was only available for Audits 2 and 3 (Table 3). Some factors such as missed breaks, or inadequate cryotherapy, could be avoided by more thorough examination and treatment. ${ }^{8}$ However, PVR might arise from overvigorous cryotherapy. ${ }^{9}$ There is clearly a balance to strike between under and over-treatment. In this context the marked reduction in the proportion of conventional operations, which were 'open', is interesting. It could imply a more conservative approach to conventional surgery in the later audit, but is more likely to be a consequence of vitrectomy being used in the more challenging cases.

\section{Functional outcome}

Anatomical reattachment is a reasonable surgical goal, but functional outcome is potentially a more important quality indicator. Visual acuity is the only functional indicator for which data are available (Tables 6 and 7). Our visual acuity results show statistically significant differences only for the middle group of postoperative acuities (6/18 to 6/36), rising from $18 \%$ in Audit 1 to $29 \%$ in Audit 3. The slight reduction in those with the best postoperative acuities (6/12 or better), from $55 \%$ to $49 \%$, is a cause for concern although the change was not statistically significant and there was a similar nonsignificant trend (from $27 \%$ to $20 \%$ ) to fewer patients with the worst postoperative vision of $6 / 60$ or less. It is possible that a potential improvement in the best acuity group in Audit 3 was masked by the failure to record all final acuities with best refraction. The trend to better results with macula-off detachments in Audit 3 (Table 7) is encouraging but not statistically significant. (Note: macula status was recorded from the latest information in the notes in this retrospective study. Sometimes this was on presentation, sometimes at surgery or in the intervening period.)

\section{'Simple' detachments}

The results of the national audit of retinal detachment surgery suggested that there may be a subgroup of 'simple' detachments in which the surgical results from general ophthalmic teams may be as good as those from V-R specialists. ${ }^{9}$ The present study does not support this view; the specialist teams achieved markedly better anatomical results even in single-hole one or two quadrant cases. If confirmed elsewhere this has important consequences in relation to the planning of ophthalmic services, particularly in relation to macula-on detachments which are generally regarded as rather urgent. It is noted that a prospective national project is currently in progress to assess the impact of surgical delay on visual outcome in macula-on cases. 


\section{Definition of VR 'specialist'}

In this study the V-R surgeons had a major V-R workload involving at least half of their working week by Audit 3. The concept of a 'specialist' is likely to require definition at a local level to take account of expertise and personnel available; it may rely predominantly on the throughput of a particular surgeon or indeed on his/her audited results. ${ }^{10}$

\section{Conclusion}

A significant improvement in anatomical success rate in retinal detachment surgery, in association with increasing subspecialisation, has been shown. This may in part relate to the greater range of surgical techniques available to the specialist surgeon. It has not been possible to identify any subgroup of 'simple' cases in which success rates are similar between specialists and generalists. This has major potential implications in regard to the organisation of ophthalmic services.

\section{References}

1 Chignell AH, Fison LG, Davies EWG, Hartley RE, Gundry MF. Failure in retinal detachment surgery. $\mathrm{Br} J$ Ophthalmol 1973; 57: 525-530.
2 Tornquist R, Tornquist P. Retinal detachment. A study of a population-based patient material in Sweden 1971-1981. III Surgical results. Acta Ophthalmologica 1988; 66: 630-636.

3 Sullivan PM, Luff AJ, Aylward GW. Results of primary retinal reattachment surgery: a prospective audit. Eye 1997; 11: 869-871.

4 Comer MB, Newman DK, George ND, Martin KR, Tom $\mathrm{BDM}$, Moore AT. Who should manage primary retinal detachments? Eye 2000; 14: 572-578.

5 Thompson JA, Chignell AH, Snead MP, Billington B, Barrie T, Thompson JR. National audit of the outcome of primary surgery for rhegmatogenous retinal detachment: differences in re-attachment rates. Presented at the Royal College of Ophthalmologists (UK) annual Congress, Harrogate, England. 23 May 2000.

6 Laidlaw DAH, Clark B, Grey RHB, Markham RHC. Letter. Eye 1998; 12: 751.

7 Wong D, McGalliard J. Are we getting better at treating retinal detachment? Technology, referral pattern or primary care? Eye 1997; 11: 763-764.

8 Richardson EC, Verma S, Green WT, Woon H, Chignell AH. Primary vitrectomy for rhegmatogenous retinal detachment: an analysis of failure. Eur J Ophthalmol 2000; 10: $160-166$.

9 Pastor JC. Proliferative vitreoretinopathy: an overview. Surv Ophthalmol 1998; 43: 3-18.

10 Chang BYP, Spencer SR. Letter. Eye 2001; 15: 819. 